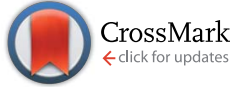

Cite this: RSC Adv., 2015, 5, 80829

\section{Synthesis and application of polypyrrole coated tenorite nanoparticles (PPy@TN) for the removal of the anionic food dye 'tartrazine' and divalent metallic ions viz. $\mathrm{Pb}(\mathrm{II}), \mathrm{Cd}(\mathrm{II}), \mathrm{Zn}(\mathrm{II}), \mathrm{Co}(\mathrm{II}), \mathrm{Mn}(\mathrm{II})$ from synthetic wastewater $\uparrow$}

\begin{abstract}
Varsha Srivastava, ${ }^{\star a}$ Philipp Maydannik, ${ }^{a}$ Y. C. Sharma ${ }^{\mathrm{b}}$ and Mika Sillanpääa
The present study deals with the synthesis of polypyrrole coated tenorite nanoparticles. The synthesized nanoparticles were characterized by XRD, TEM, SEM and EDS. TEM images showed the formation of nanoparticles with 26-30 nm diameter. The BET surface area of the nanoparticles was determined to be $425 \mathrm{~m}^{2} \mathrm{~g}^{-1}$ while the pore diameter of the nanoparticles was found to be $3.57 \mathrm{~nm}$ which showed the formation of mesoporous nanoparticles. The $\mathrm{pH}_{\mathrm{zpc}}$ of the nanoparticles was determined to be 4.4. The removal efficiency of the synthesized nanoparticles for an anionic food dye 'tartrazine' was investigated. Decreased removal was observed, when the dye concentration was increased from 100 to $200 \mathrm{mg} \mathrm{L}^{-1}$. It was observed that an acidic medium was favorable for tartrazine removal. A thermodynamic study suggested the endothermic nature of tartrazine adsorption. The value of $E_{a}$ for the present system was found to be $26.97 \mathrm{~kJ} \mathrm{~mol}^{-1}$. The best suitable kinetic model was well explained by the pseudo second order model. Langmuir adsorption capacity was measured to be $42.50 \mathrm{mg} \mathrm{g}^{-1}$. Exhausted (dye loaded) nanoparticles were used as an efficient adsorbent for the removal of divalent metallic ions viz. $\mathrm{Pb}(॥)$, $\mathrm{Cd}(॥), \mathrm{Co}(॥), \mathrm{Mn}(॥), \mathrm{Zn}(॥)$ and were found to be efficient for the removal of metallic species from a single solute system as well as a multi-solute system. This study reveals that polypyrrole coated tenorite nanoparticles are very efficient for dye removal and the dye loaded exhausted adsorbent is equally good for metal removal because tartrazine loading on nanoparticles makes the surface suitable for metal interaction. Thus, the synthesized nanoparticles prove to be a good candidate for the treatment of dye and metal bearing wastewater.
\end{abstract}

Received 17th July 2015

Accepted 15th September 2015

DOI: $10.1039 / \mathrm{c} 5 \mathrm{ra} 14108 \mathrm{~g}$

www.rsc.org/advances agent. ${ }^{6}$ Tartrazine is also used in the shells of medicinal capsules, cosmetics, vitamins and syrups. ${ }^{7,8}$ Tartrazine $\left(\mathrm{C}_{16} \mathrm{H}_{9} \mathrm{~N}_{4} \mathrm{Na}_{3} \mathrm{O}_{9} \mathrm{~S}_{2}\right)$ is an anionic dye which releases anions in an aqueous medium (Fig. 1). ${ }^{9}$

Though, tartrazine is used in variety of food materials, but its higher amount can pose mutagenic and carcinogenic effects. ${ }^{\mathbf{5 , 8 1 0}}$ Other health problems which can arise due to excess inhalation of tartrazine are asthma, migraine, itching, hypersensitivity, thyroid cancer, blurred vision and skin eczema. Due to the toxic nature of dyes, much attention should be paid for proper treatment of dye bearing wastewater before being<smiles>CC(=O)c1nn(-c2ccc(OS(=O)(=O)O[Na])cc2)c(O)c1/N=N/c1ccc(OS(=O)(=O)O[Na])cc1</smiles>

Fig. 1 Structure of tartrazine dye. ${ }^{9}$
${ }^{a}$ Laboratory of Green Chemistry, Faculty of Technology, Lappeenranta University of Technology, Sammonkatu 12, Mikkeli, FI-50130, Finland. E-mail: varshao6bhu@ gmail.com; varsha.srivastava@lut.fi; Tel: +358 414712348

${ }^{b}$ Department of Chemistry, Indian Institute of Technology, Banaras Hindu University, Varanasi 221005, India

$\dagger$ Electronic supplementary information (ESI) available. See DOI: $10.1039 / \mathrm{c} 5 \mathrm{ra} 14108 \mathrm{~g}$ aqueous streams. ${ }^{3,5}$ Among the various dyes, tartrazine is commonly used in a variety of food materials as a coloring 
discharged into the water stream. Several techniques viz. precipitation, ozonation, reverse osmosis, ion-exchange, membrane filtration, electrochemical oxidation, coagulation, flocculation and adsorption have been developed for the treatment of dye-containing effluents. ${ }^{\mathbf{1 , 6 , 1 1}}$ However, most of these technologies are expensive and not highly efficient for the treatment of a wide range of dye containing wastewater.

Among these methods, adsorption technique has been considered to be cost effective and efficient technique for the treatment of dye loaded wastewater. ${ }^{3,12,13}$ Variety of adsorbents have been discovered and used for the treatment of dye laden wastewater., 14,15 Among them, activated carbon is the most widely used adsorbent to remove different kinds of dyes from wastewater because of its high adsorption capacity, but at the same time its high cost has always inspired the scientists to discover new adsorbent materials. Recently, nanosized materials have emerged as a strong competitor of conventional adsorbent materials due to their unique properties such as the large surface area to volume ratio, chemical stability, etc. and have attracted attention of several researchers to develop varieties of nanomaterials for water treatment process. ${ }^{16,17}$ Properties of nanomaterial can be further improvised by chemical modification according to pollutant species which makes it a strong candidate for treatment of both organic and inorganic pollutants. ${ }^{18,19}$ Polypyrrole modified adsorbent materials were found to be very efficient in removal of nitrophenols, reactive blue 19, alizarin red-S, alizarin yellow GG etc. ${ }^{\mathbf{2 0 , 2 1}}$ In the present study, polypyrrole coated tenorite (PPy@TN) nanoparticles were synthesized and characterized by different techniques.PPy@TN nanoparticles were used for the removal of an anionic food dye 'tartrazine dye' (TZ) from synthetic wastewater. The effect of various important parameters was investigated and optimum conditions for maximum removal were determined. After dye adsorption, tartrazine loaded nanoparticles (TZ-PPy@TN) were used as adsorbent material for the treatment of divalent metallic ions from synthetic wastewater.

\section{Materials and method}

\subsection{Synthesis of polypyrrole coated tenorite (PPy@TN) nanoparticles}

Synthesis of PPy@TN can be divided into two parts (a) synthesis of tenorite nanoparticles (TN) and (b) modification of tenorite nanoparticles with polypyrrole (PPy@TN).

(a) For the synthesis of tenorite nanoparticles, the copper nitrate solution was precipitated by adding ammonia solution drop by drop into $0.5 \mathrm{M}$ copper nitrate solution. After precipitation, precipitate $\left(\mathrm{Cu}(\mathrm{OH})_{2}\right)$ was separated by centrifugation and washed several times with ultrapure water. After proper washing, the precipitate was dried in hot air oven at $60^{\circ} \mathrm{C}$. Dried precipitate was then calcined at $400{ }^{\circ} \mathrm{C}\left( \pm 0.2{ }^{\circ} \mathrm{C}\right)$ for $2 \mathrm{~h}$ in the Muffle furnace (NABERTHERM B-170) by maintaining heating rate of $5{ }^{\circ} \mathrm{C} \mathrm{min}^{-1}$ to get tenorite nanoparticles.

(b) For synthesis of PPy@TN nanoparticles, $5 \mathrm{~g}$ of tenorite nanoparticles were sonicated in $150 \mathrm{~mL}$ of ultrapure water and then $5 \mathrm{~mL}$ of pyrrole was added into this solution and stirred for 15 min. After stirring, $\mathrm{FeCl}_{3}$ solution (oxidizing agent) was added drop by drop into this mixture solution and again stirred for $5 \mathrm{~h}$ on a magnetic stirrer at room temperature. The colour of solution changed from brown to black on adding $\mathrm{FeCl}_{3}$. After a sufficient contact time, polypyrrole coated tenorite nanoparticles were separated from the solution by centrifugation at $5000 \mathrm{rpm}$ for $15 \mathrm{~min}$ and multistep washing was carried out for the removal of another product $\left(\mathrm{FeCl}_{2}\right)$ which was formed during the reaction of pyrrole and $\mathrm{FeCl}_{3}$. Separated PPy@TN nanoparticles were dried and grounded in tube mill and sieved to remove lumps of particles formed during the drying process.

Tenorite nanoparticles, PPy@TN and dye loaded nanoparticles (TZ-PPy@TN) were characterized by transmission electron microscopy (TEM), X-ray diffraction (XRD), energydispersive X-ray spectroscopy (EDS) and scanning electron microscopy (SEM). PPy@TN nanoparticles were used for the removal of tartrazine dye from synthetic wastewater. Dye loaded nanoparticles were used for the treatment of divalent metallic ions from synthetic wastewater. XRD patterns of nanoparticles were recorded on a PANALYTICAL X-ray diffractometer using Co $\mathrm{K} \alpha$ radiation $(\lambda=1.790307 \AA)$ operated at $40 \mathrm{kV}$ and $40 \mathrm{~mA}$ in the $2 \theta$ range of $15-100^{\circ}$. The particle size and morphology of the samples were determined by using TEM images taken with a Hitachi H-7600 TEM with an acceleration voltage of $200 \mathrm{kV}$. The surface morphology was studied by SEM analysis, using the Hitachi S-4800 system with an acceleration voltage of 20 and $30 \mathrm{kV}$. Elemental analysis of nanoparticles was examined by EDS. FTIR images of tenorite nanoparticles and PPy@TN nanoparticles were recorded in the range of 400 to $4000 \mathrm{~cm}^{-1}$ (ATR-FTIR, Bruker Vertex 70 model) to investigate the changes in tenorite nanoparticles due to modification with polypyrrole nanoparticles. For determination of BET surface area, nitrogen adsorption-desorption measurements were conducted at $77 \mathrm{~K}$ with a Quantachrome instrument. The powders were degassed in vacuum at $150{ }^{\circ} \mathrm{C}$ for $24 \mathrm{~h}$ prior to the measurement. $\mathrm{pH}_{\mathrm{zpc}}$ of nanoparticles was determined by earlier reported method. ${ }^{22}$ In brief, $0.01 \mathrm{M} \mathrm{NaCl}$ solutions of different $\mathrm{pH}$ ranging from 2 to 12 were prepared. $0.20 \mathrm{~g}$ of nanoparticles were placed in $\mathrm{NaCl}$ solution of different $\mathrm{pH}$ and solution was kept for $48 \mathrm{~h}$ and then nanoparticles were separated from $\mathrm{NaCl}$ solution and the $\mathrm{pH}$ of the solution was measured. A graph between initial $\mathrm{pH}$ and final $\mathrm{pH}$ was plotted and the intersection of initial and final $\mathrm{pH}$ was recorded as $\mathrm{pH}_{\mathrm{zpc}}$ of adsorbent.

\subsection{Treatment of tartrazine bearing synthetic wastewater}

Removal study of tartrazine (TZ) from synthetic wastewater was performed in a batch process to optimize various important parameters such as contact time, concentration, dose, $\mathrm{pH}$ and temperature. Stock solution $\left(1000 \mathrm{mg} \mathrm{L}^{-1}\right)$ of $\mathrm{TZ}$ was prepared by dissolving required amount of $\mathrm{TZ}$ in ultrapure water. $\mathrm{TZ}$ solution with different concentration ranges (100 to $200 \mathrm{mg} \mathrm{L}^{-1}$ ) were prepared by diluting the stock solution. $\mathrm{pH}$ of $\mathrm{TZ}$ solutions was adjusted by adding $0.1 \mathrm{M} \mathrm{HCl} / \mathrm{NaOH}$ solution. Adsorption experiments were conducted with different dye concentration (100-200 $\mathrm{mg} \mathrm{L}^{-1}$ ), dosage ( 1 to $10 \mathrm{~g} \mathrm{~L}^{-1}$ ), temperature (293$323 \mathrm{~K})$ and $\mathrm{pH}(2.0$ to 12.0$)$ to investigate the effect of each variable on $\mathrm{TZ}$ removal from synthetic wastewater. For batch 
experiments, $1 \mathrm{~g} \mathrm{~L}^{-1}$ of PPy@TN nanoparticle was added into dye solution and agitated at room temperature in a temperature controlled shaker. Treated dye solutions were collected at different time intervals to determine the equilibrium time. Nanoparticles were separated from the dye solution by centrifugation at $4000 \mathrm{rpm}$ for $10 \mathrm{~min}$ and the absorbance of supernatant solution was recorded by UV-visible spectrophotometer at $\lambda_{\max } 430 \mathrm{~nm}$ for residual dye concentration. ${ }^{8}$ The removal (\%) of dye and the amount of dye adsorbed were calculated by following equations.

$$
\begin{gathered}
\text { Removal of dye }(\%)=\left(\frac{C_{\mathrm{i}}-C_{\mathrm{e}}}{C_{\mathrm{i}}}\right) \times 100 \\
q_{\mathrm{e}}=\left(\frac{C_{\mathrm{i}}-C_{\mathrm{e}}}{W}\right) \times V
\end{gathered}
$$

where $C_{\mathrm{i}}\left(\mathrm{mg} \mathrm{L}^{-1}\right)$ and $C_{\mathrm{e}}\left(\mathrm{mg} \mathrm{L}^{-1}\right)$ are the initial and equilibrium concentrations of dye respectively. $q_{\mathrm{e}}\left(\mathrm{mg} \mathrm{g}^{-1}\right)$ is the amount adsorbed on per unit mass of the adsorbent at equilibrium, $W$ is the mass of adsorbent $(\mathrm{g})$ and $V(\mathrm{~L})$ is the volume of solution. Dye loaded nanoparticles were further used as adsorbent for the removal of metallic ions viz. $\mathrm{Pb}$ (II), $\mathrm{Cd}$ (II), $\mathrm{Co}(\mathrm{II}), \mathrm{Mn}$ (II), Zn(II) from synthetic wastewater. For this study, the single solute solution of four different concentration ranges viz. $75,100,125$ and $150 \mathrm{mg} \mathrm{L}^{-1}$ were prepared by adding the appropriate amounts of their salt into ultrapure water. Multisolute metal solution of $100 \mathrm{mg} \mathrm{L}^{-1}$ was also prepared to observe the adsorption capacity of nanoparticle for different metals in a multisolute system. The residual concentration of metal was determined by ICP-OES spectrometer.

\section{Result and discussions}

\subsection{Characterization of nanoparticles}

XRD analysis of tenorite nanoparticle, polypyrrole coated tenorite nanoparticles (PPy@TN) and tartrazine loaded nanoparticles (TZ-PPy@TN) are shown in Fig. 2. In Fig. 2a, all peaks correspond to the tenorite phase of $\mathrm{CuO}$ and all the diffraction peaks can be indexed to tenorite phase of $\mathrm{CuO}$ which is in good agreement with the reference data (ICPDS data 98-001-6025). It is clear from XRD of polypyrrole coated tenorite nanoparticles that polypyrrole has modified the tenorite nanoparticles and new peaks appear in the modified sample due to polypyrrole reaction (Fig. 2b). However, intensity of characteristic peaks of nano tenorite is very low in the coated sample. According to EDS analysis of tenorite nanoparticles, the $\mathrm{Cu} / \mathrm{O}$ atomic ratio $(\mathrm{Cu}=$ $51.02 \%$; $\mathrm{O}=48.98 \%$ ) was 1.04 (Fig. 2a-1). Elemental composition of PPy@TN nanoparticle is different from tenorite nanoparticles, which shows the modification of tenorite nanoparticles (Fig. 2b-1). Further, elemental composition of TZ-PPy@TN nanoparticles shows the presence of other elements like $\mathrm{N}$ and $\mathrm{S}$ which is due to dye loading (Fig. 2c-1). TEM images of nano tenorite, PPy@TN and TZ-PPy@TN nanoparticles are shown in Fig. 3.

The TEM image of nano tenorite shows the formation of well dispersed hexagonal and spherical nanoparticles with mean diameter $\sim 23-45 \mathrm{~nm}$. After polypyrrole coating, some tube like and brick like structures appeared having diameter in the range of 26-30 nm. In TZ-PPy@TN nanoparticles, almost all particles have similar morphology like a small tube structure ( 5-11 nm). Further, surface morphology was investigated by SEM. SEM images of nano tenorite and PPy@TN and TZ-PPy@TN nanoparticles are given in Fig. 4. SEM of nano tenorite also shows that the particle morphology is spherical and hexagonal (Fig. 4a and b). SEM images of PPy@TN nanoparticles showed different morphology, which indicates that polypyrrole completely modified the surface of tenorite nanoparticles (Fig. 4c and d). Highly agglomerated particles can be seen in TZ-PPy@TN nanoparticles (Fig. 4e and f). FTIR of tenorite nanoparticle, PPy@TN and TZ-PPy@TN further is shown in Fig. S1 (in ESI†). FTIR results clearly indicates that polypyrrole totally changed surface properties of tenorite nanoparticles (in ESI, Section S1†).

$\mathrm{N}_{2}$ adsorption and desorption isotherms of nanoparticles are shown in Fig. 5. BET surface area of synthesized nanoparticles was determined to be $425 \mathrm{~m}^{2} \mathrm{~g}^{-1}$, while pore volume and pore diameter were $0.38 \mathrm{~cm}^{3} \mathrm{~g}^{-1}$ and $3.57 \mathrm{~nm}$ respectively. Value of pore diameter suggested the formation of mesoporous nanoparticles.

BET surface area of tenorite nanoparticles and TZ-PPy@TN nanoparticles were calculated with their $\mathrm{N}_{2}$ adsorption and desorption isotherms (in ESI Fig. S2a and S2b†). BET surface area, pore volume and pore diameter of tenorite nanoparticles were calculated to be $6.56 \mathrm{~m}^{2} \mathrm{~g}^{-1}, 0.002 \mathrm{~cm}^{3} \mathrm{~g}^{-1}$ and 1.107 $\mathrm{nm}$ respectively while BET surface area of TZ-PPy@TN were determined to be $51.49 \mathrm{~m}^{2} \mathrm{~g}^{-1}$. Decreased surface area of TZ-PPY@TN in comparison of PPy@TN nanoparticles is due to loading of dye molecules on PPy@TN nanoparticles. Pore volume for TZ-PPy@TN was recorded to be $0.013 \mathrm{~cm}^{3} \mathrm{~g}^{-1}$ while pore diameter was found to be $0.99 \mathrm{~nm}$.

\subsection{Adsorption studies}

3.2.1. Effect of contact time and initial dye concentration. The contact time is the most important design parameter. The appropriate contact time between adsorbent and adsorbate during the adsorption process is necessary to achieve maximum removal of pollutant species. In this view, dye solution was agitated with adsorbent for different time intervals from $15 \mathrm{~min}$ to $420 \mathrm{~min}$.

It was observed that initial removal rate is very rapid and approximately $87 \%( \pm 0.01)$ of dye were removed within $15 \mathrm{~min}$. Removal of dye rapidly increased up to $180 \mathrm{~min}$ and thereafter up to $300 \mathrm{~min}$ of contact time, we get approximately the same result and further no change in removal percentage was observed upto $420 \mathrm{~min}$. This behavior is due to availability of plenty of adsorption sites at the initial stage. After equilibrium time $(300 \mathrm{~min})$, there is no change in the removal of dye so 300 min contact time was selected for all other experimental setup. To see the effect of initial concentration on the removal of dye, batch experiments with different dye concentration ranges were carried out at equilibrium time and the plot of adsorption capacity $\left(q_{\mathrm{e}}\right) /$ removal $(\%)$ versus different TZ concentration is shown in Fig. 6. Removal of dye decreased on 

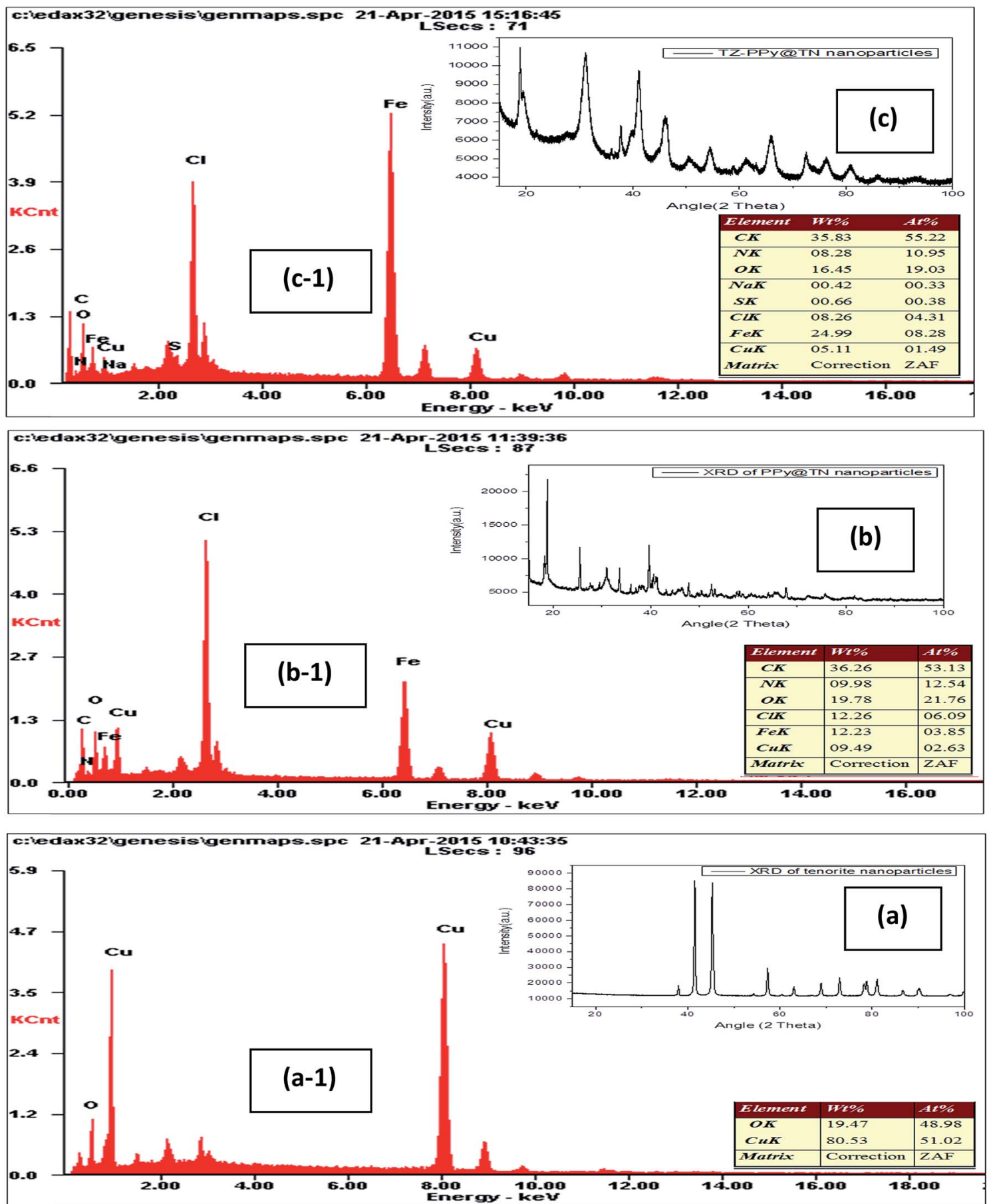

Fig. 2 XRD of (a) nano tenorite; (b) polypyrrole coated tenorite nanoparticles (PPy@TN); (c) tartrazine loaded nanoparticles (TZ-PPy@TN); (a-1) EDS of nano tenorite; (b-1) polypyrrole coated tenorite nanoparticles (PPy@TN); (c-1) tartrazine loaded nanoparticles (TZ-PPy@TN).

increasing dye concentration. At lower initial concentration, excess adsorption sites are available for dye molecules, but for higher concentration of dye, the ratio of adsorbent sites are reduced in comparison to available dye molecules and all the binding sites easily get saturated due to the higher concentration of dye molecules in the solution resulting in the decreased removal at higher concentration. Further, the residual dye concentration is higher for higher dye concentrations. At a fixed nanoparticle dose, the amount of dye adsorbed increased from 29.28 to $41.27 \mathrm{mg} \mathrm{g}^{-1}( \pm 0.01)$ by increasing concentration of dye solution from 100 to $200 \mathrm{mg} \mathrm{L}^{-1}$. In case of lower concentration most of the adsorption sites remain unoccupied due to less number of dye molecules while for higher concentration most of the binding sites were occupied by a dye molecule resulting in higher adsorption capacity in comparison to lower concentration. 

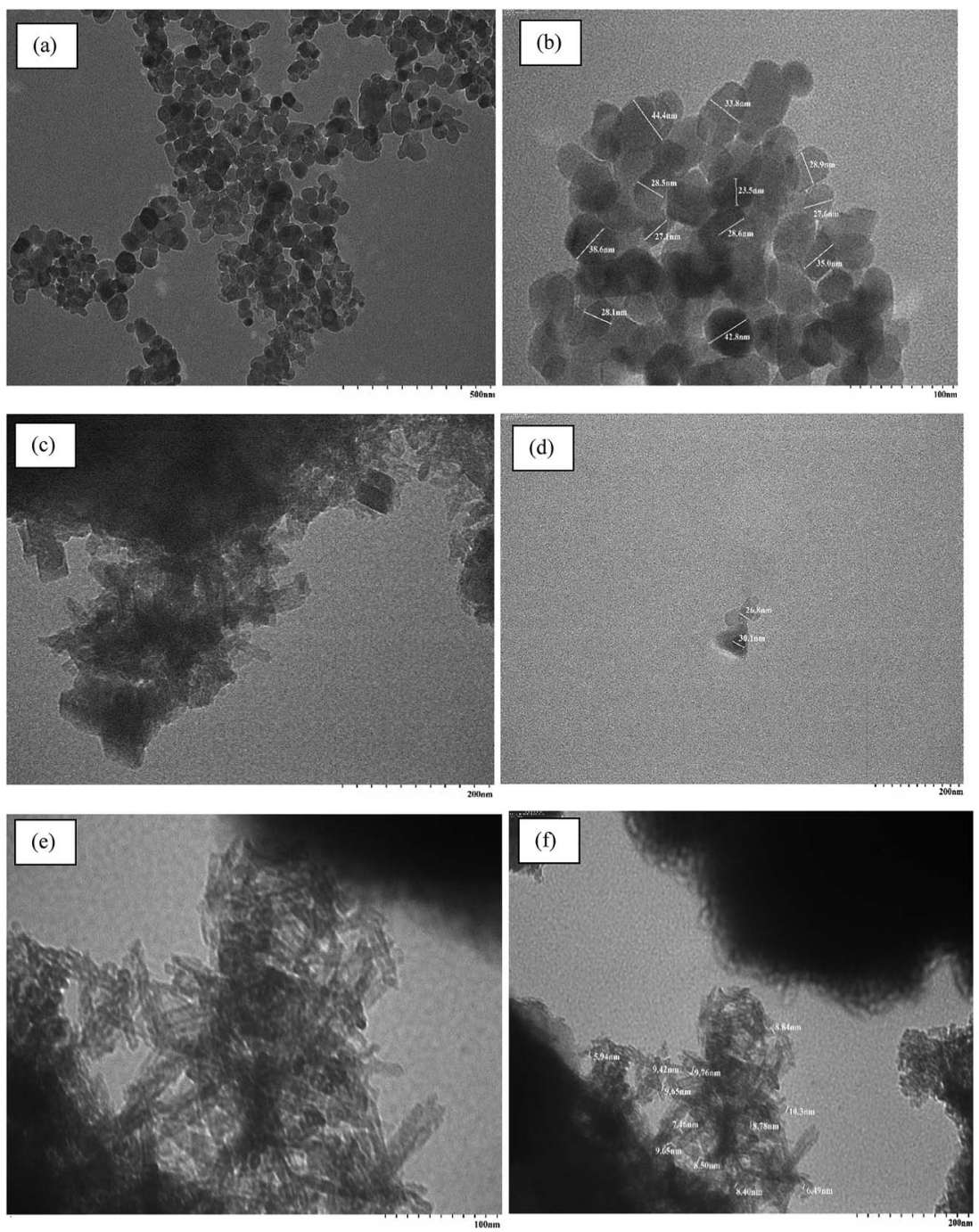

Fig. 3 ( $a$ and b) TEM of nano tenorite; (c and d) PPy@TN and (e and f) TZ-PPy@TN

3.2.2. Effect of $\mathrm{pH}$ on removal of tartrazine. Solution $\mathrm{pH}$ is an important factor which is responsible for the adsorbent surface charge and the degree of ionization. Effect of solution $\mathrm{pH}$ on removal of $\mathrm{TZ}$ was assessed by varying $\mathrm{pH}$ in the range of 2.0 to 12 by keeping the other experimental conditions constant (100 mg L ${ }^{-1}$; $200 \mathrm{rpm}$; $293 \mathrm{~K}$; $0.05 \mathrm{~g}$ per $15 \mathrm{~mL}$ dose, contact time $300 \mathrm{~min}$ ). The effect of solution $\mathrm{pH}$ on removal of $\mathrm{TZ}$ is shown in Fig. 7a. It was observed that the removal of dye was higher in acidic medium in comparison to alkaline medium. Similar findings were also reported by Mittal et al. (2007). ${ }^{6}$ Removal decreased from 99.28 to $73.88 \%( \pm 0.01)$ on increasing $\mathrm{pH}$ from 2.0 to 12.0. $\mathrm{pH}_{\mathrm{zpc}}$ of PPy@TN was recorded to be 4.4 (Fig. 7b). When the $\mathrm{pH}$ of solution is lower than $\mathrm{pH}_{\mathrm{zpc}}$ of adsorbent, surface will be positively charged but as $\mathrm{pH}$ goes above $\mathrm{pH}_{\mathrm{zpc}}$, number of negatively charged adsorbent surface sites increases. In aqueous solution, tartrazine releases sodium ions and sulfonate anions. In acidic medium, due to positively charged surface sulfonate anions can be easily adsorbed (Fig. 7c).

Further, in acidic medium, high degree of surface protonation favors electrostatic attraction between positively charged adsorbent surfaces and negatively charged anionic sulfonate groups. In contrast, at higher $\mathrm{pH}$ values $\left(\mathrm{pH}>\mathrm{pH}_{\mathrm{zpc}}\right)$, the adsorbent surface becomes more negatively charged.

In alkaline medium, excess amount of $-\mathrm{OH}^{-}$ions compete with the negatively charged anionic species and electrostatic repulsion between the anionic species and the negatively charged surface sites is increased, resulting in the decreased removal of TZ.

3.2.3. Effect of adsorbent dose on removal of $\mathbf{T Z}$ dye. The adsorbent dose is an important parameter which can affect the removal of pollutants. The effect of adsorbent dose on removal of TZ was investigated by adding different amounts of dose ( 1 to $10 \mathrm{~g} \mathrm{~L}^{-1}$ ) into dye solution of $100 \mathrm{mg} \mathrm{L}^{-1}$ and agitating at $200 \mathrm{rpm}$ for $300 \mathrm{~min}$. After equilibrium time, the TZ solution was separated from adsorbent by centrifugation and the residual concentration in the supernatant dye solution was analyzed. The plot of $\mathrm{TZ}$ removal (\%) versus dose $\left(\mathrm{g} \mathrm{L}^{-1}\right)$ is shown in Fig. 8. The removal of TZ increased rapidly from 74.50 to $98.89 \%( \pm 0.02)$ by increasing adsorbent dose from $1 \mathrm{~g} \mathrm{~L}^{-1}$ to $3.3 \mathrm{~g} \mathrm{~L}^{-1}$ and after that there was not any significant change in 

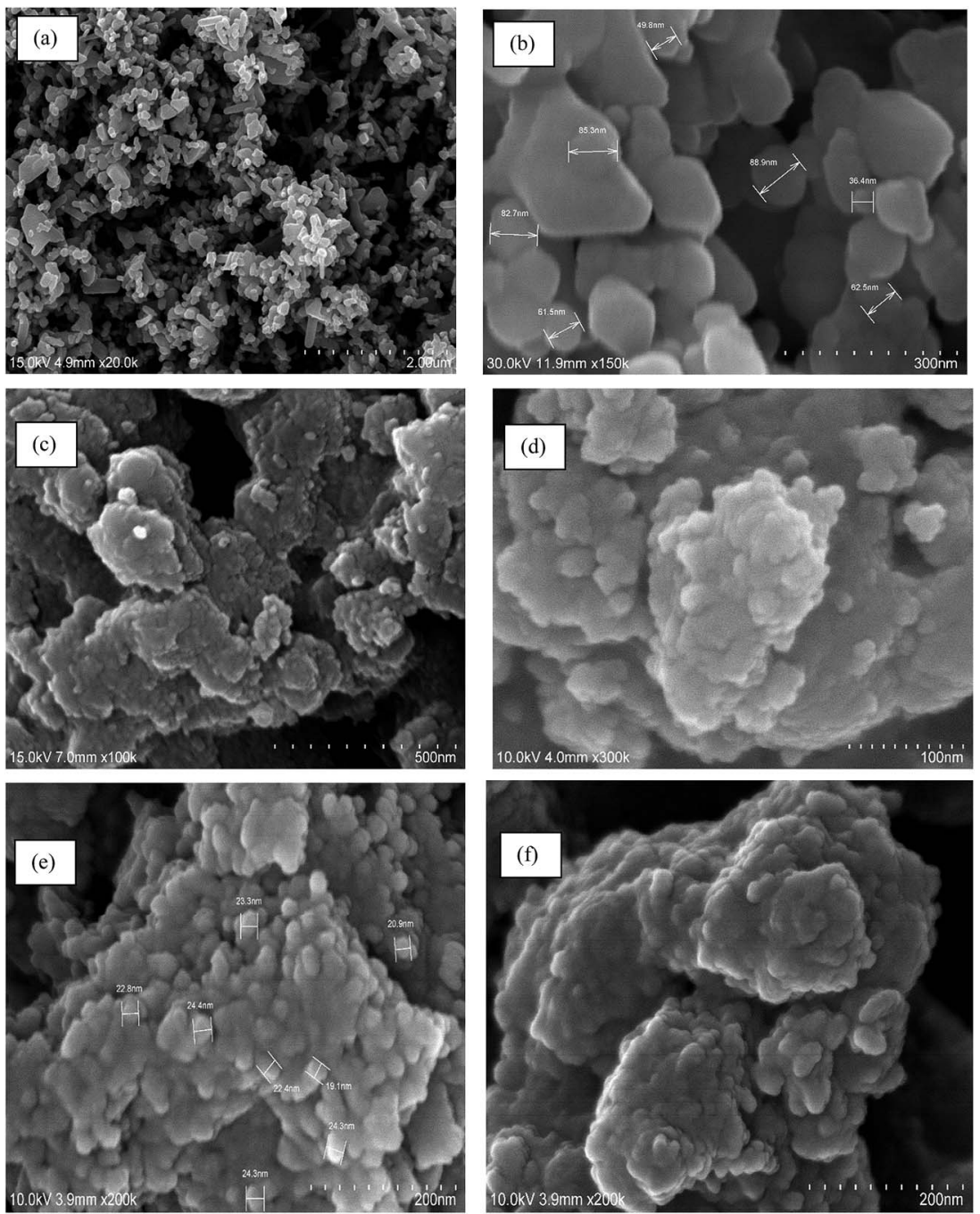

Fig. 4 ( $a$ and b) SEM of nano tenorite; (c and d) PPy@TN; (e and f) TZ-PPy@TN.

removal percentage of TZ. Approximately similar result was observed even at higher adsorbent dose. This behavior is obvious because on increasing adsorbent dose initially, removal increased due to the availability of more active sites for a fixed amount of dye concentration. However, adsorption capacity $\left(\mathrm{mg} \mathrm{g}^{-1}\right)$ decreased with further increasing of adsorbent dose due to unsaturated surface at higher adsorbent dose for a particular concentration. Higher adsorbent dosage may also cause aggregation of adsorption sites which can decrease total available adsorbent surface for adsorbate interaction. ${ }^{23}$

\section{Kinetic modelling of tartrazine removal process}

The study of adsorption kinetics is necessary for understanding the mechanism of adsorption process and also gives an idea about the rate at which a pollutant species is removed from aqueous solutions. ${ }^{24}$ Several processes may be involved in the removal of any pollutant species such as pore diffusion, film diffusion and intraparticle diffusion. In order to explain the adsorption mechanism, kinetic adsorption data were analyzed by using different kinetic models viz. pseudo first-order model, pseudo-second-order model, intraparticle diffusion, Boyd model and Bangham model. The kinetic data were collected for various initial dye concentrations by keeping other experimental parameters constant.

\subsection{Pseudo first order and pseudo second order model}

The values of pseudo first order and second order kinetic model were calculated from the following equations: ${ }^{25}$

$$
\begin{gathered}
\text { Pseudo first order }: \log \left(q_{\mathrm{e}}-q_{t}\right)=\log q_{\mathrm{e}}-\frac{k_{1}}{2.303} t \\
\text { Pseudo second order model : } \frac{t}{q_{t}}=\frac{1}{k_{2} q_{\mathrm{e}}{ }^{2}}+\frac{1}{q_{\mathrm{e}}} t \\
h=k_{2} q_{\mathrm{e}}{ }^{2}
\end{gathered}
$$

where $k_{1}\left(\min ^{-1}\right)$ and $k_{2}\left(\mathrm{~g} \mathrm{mg}^{-1} \min ^{-1}\right)$ are the rate constants of pseudo-first and pseudo-second order models respectively. $h$ is 


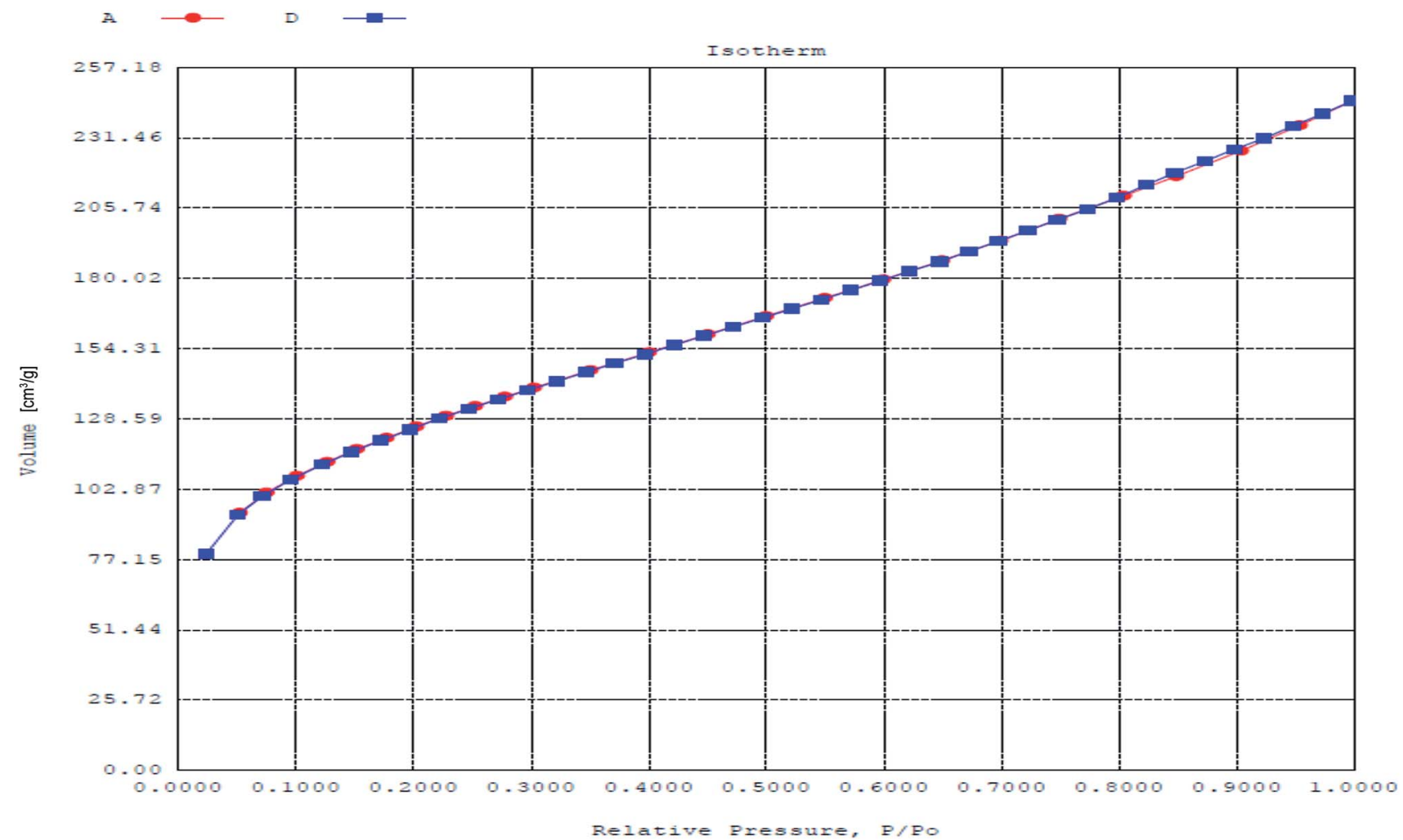

Fig. 5 Nitrogen adsorption-desorption isotherm plot for PPy@TN nanoparticles.

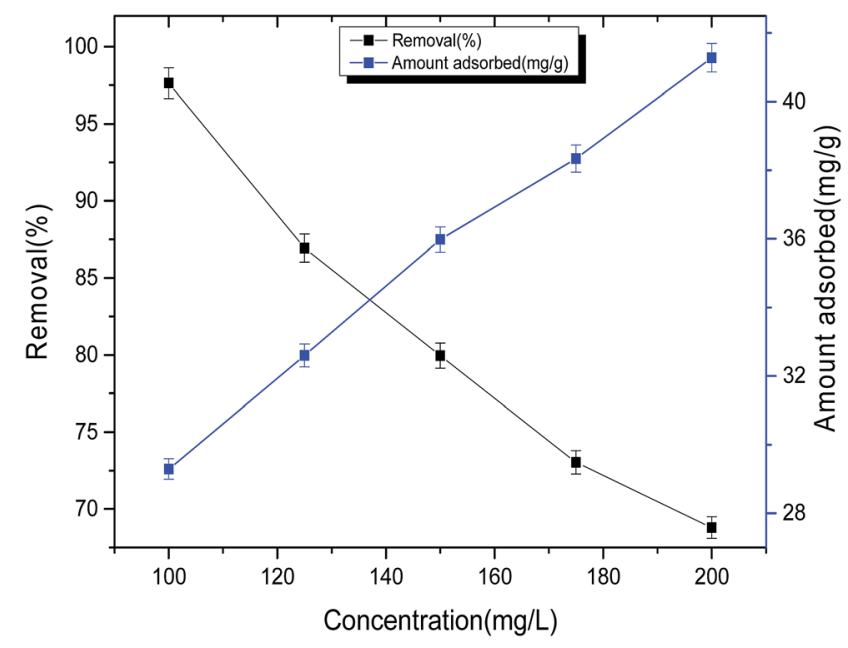

Fig. 6 Effect of initial concentration on dye removal.

known as the initial adsorption rate $\left(\mathrm{mg} \mathrm{g}^{-1} \min ^{-1}\right) \cdot q_{t}\left(\mathrm{mg} \mathrm{g}^{-1}\right)$ and $q_{\mathrm{e}}\left(\mathrm{mg} \mathrm{g}^{-1}\right)$ are the amounts of dye adsorbed at time $t$ and equilibrium respectively, $t$ is the contact time (min). The slope and intercept of the plot of $\log \left(q_{\mathrm{e}}-q_{t}\right)$ against $t$ gives the value of $k_{1}$ and $q_{\mathrm{e}}$ respectively, while the slope and intercept of the plot of $t / q_{t}$ versus $t$ gives the value of pseudo-second-order rate constant $\left(k_{2}\right)$ and the equilibrium adsorption capacity $\left(q_{\mathrm{e}}\right)$ respectively. The values of different kinetic parameters at different concentrations are shown in Table 1.
It is clear from Fig. 9a that the plots of $\log \left(q_{\mathrm{e}}-q_{t}\right)$ versus $t$ for pseudo first order kinetic model does not show good results while the plots of $t / q_{t}$ versus $t$ (Fig. 9b) gives a straight line for all the selected dye concentrations which shows the applicability of the pseudo-second order equation for $\mathrm{TZ}$ adsorption. Further, it is clear from Table 1 that $q_{\mathrm{e}}$ values calculated from pseudo-second-order model is rather comparable with experimental $q_{\mathrm{e}}$ in comparison to pseudo first order model. Calculated value of $q_{\mathrm{e}}$ is not consistent with experimental $q_{\mathrm{e}}$ values for pseudo first order model which indicates the suitability of the pseudo-second-order model. The corresponding $R^{2}$ value was greater for pseudo second order model in comparison to pseudo-first-order kinetic model which also supports the suitability of pseudo second order kinetic model. Fast removal of TZ from adsorbate solution suggested that most part of the adsorbate removed by interaction of exterior surface of adsorbent while later adsorption may be due to involvement of other process like Intraparticle and pore diffusion mechanism.

\subsection{Intraparticle diffusion model}

The possibility of intraparticle diffusion was also investigated to identify the rate determining step by applying Weber-Morris intraparticle diffusion model on kinetic data. Intraparticle diffusion model can be expressed as follows: ${ }^{26}$

$$
q_{t}=k_{\mathrm{id}} t^{0.5}+C
$$




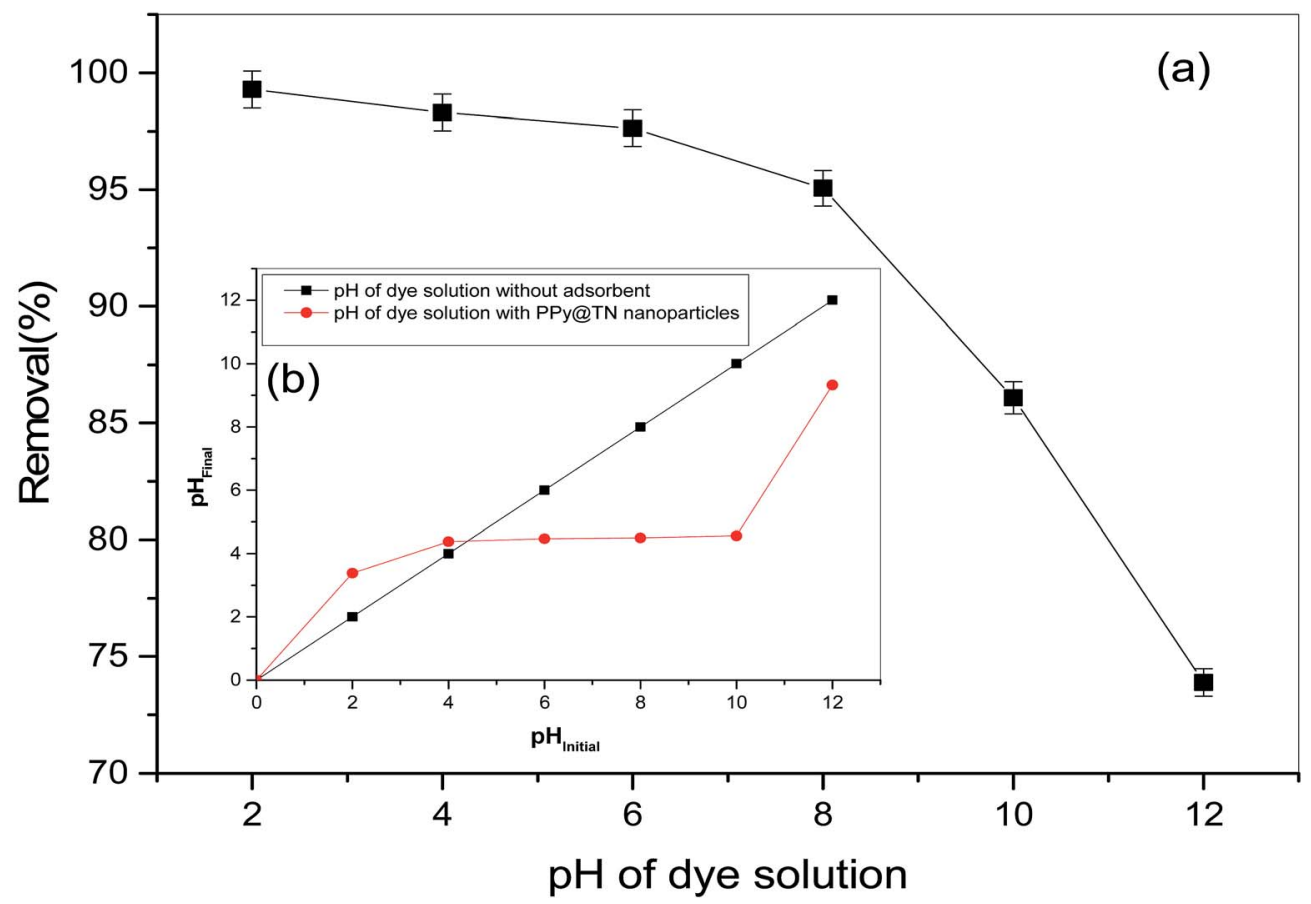

(c)
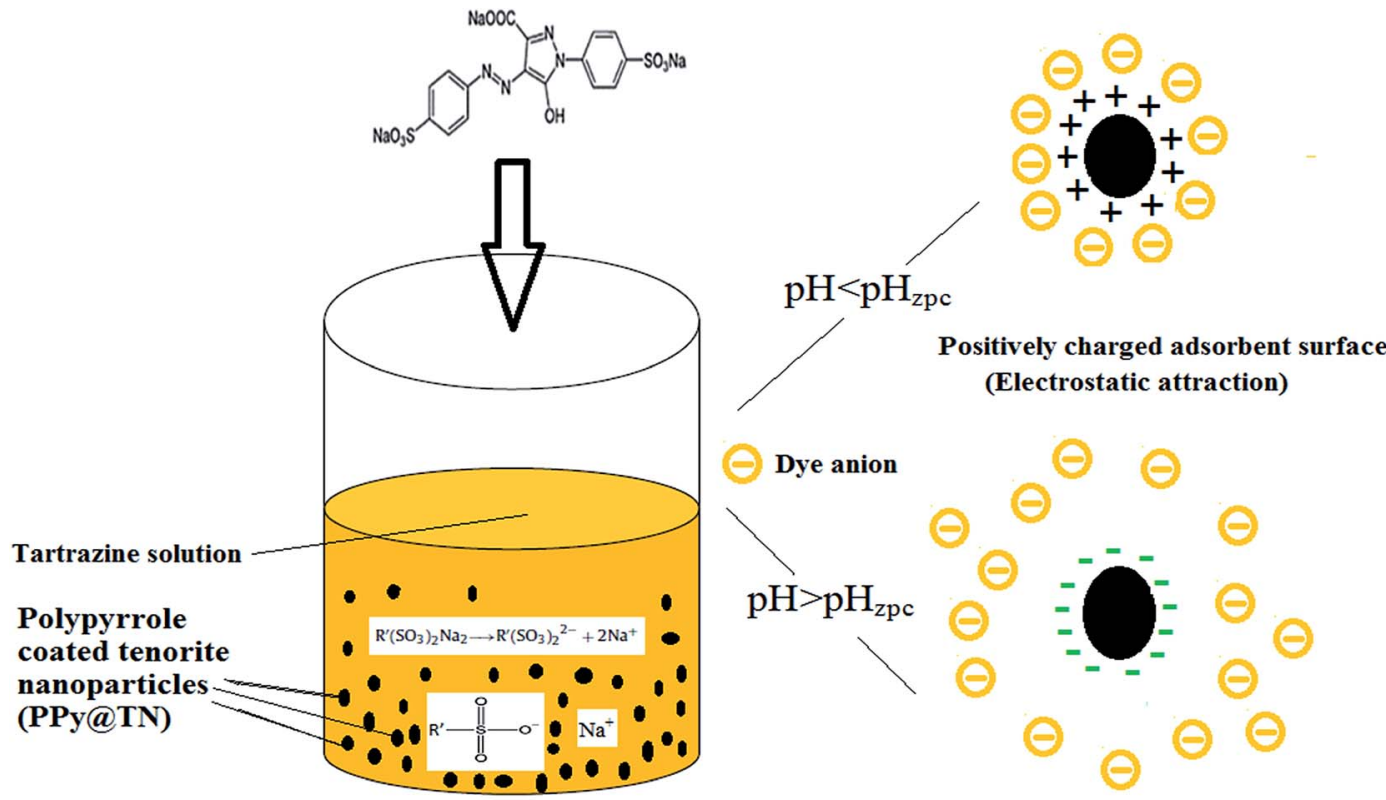

Negatively charged adsorbent surface ( Electrostatic repulsion)

Fig. 7 (a) Effect of $\mathrm{pH}$ on removal of $\mathrm{TZ}$ from synthetic wastewater (b) $\mathrm{pH}_{\mathrm{zpc}}$ of PPy@TN nanoparticles. (c) Effect of solution pH on adsorbent surface.

where $q_{t}, k_{\text {id }}$ and $C$ are the amount of adsorbed dye onto adsorbent $\left(\mathrm{mg} \mathrm{g}^{-1}\right)$ at time $t$, intraparticle diffusion rate constant and intercept $\left(\mathrm{mg} \mathrm{g}^{-1}\right)$ respectively.

The values of $k_{\mathrm{id}}$ and $C$ were calculated from the slope and intercept of plot $q_{t}$ versus $t^{0.5}$. The intercept ' $C$ ' which is proportional to boundary layer thickness, gives an idea about the thickness of the boundary layer. In case of the larger intercept, the boundary layer effect will be greater. Intraparticle diffusion usually starts when surface of adsorbent get saturated with adsorbate molecules. The value of $k_{\text {id }}$ increased with increasing dye concentration due to driving force (Table 1). Intra-particle diffusion plot for all selected concentration was found to be linear with good correlation coefficient (Fig. 10a) which indicates the possibility of intraparticle diffusion of dye 


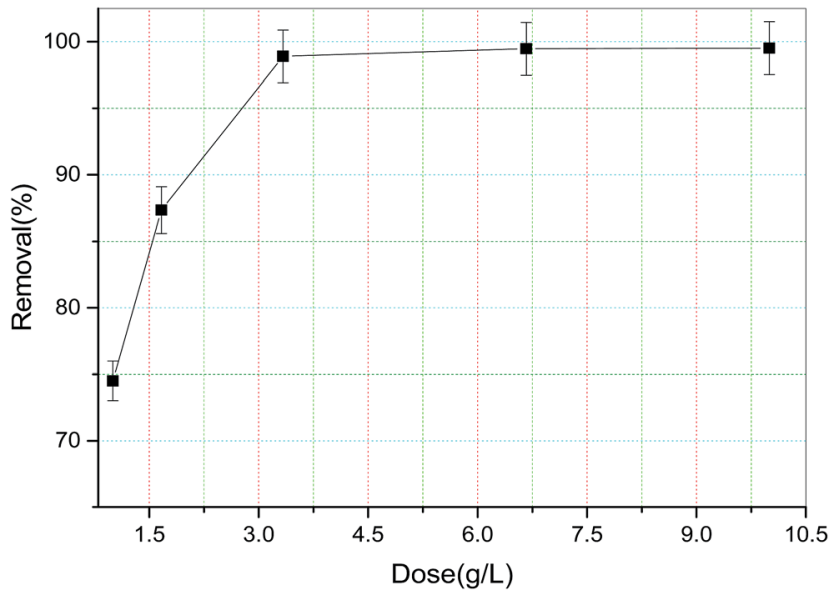

Fig. 8 Effect of adsorbent dose on TZ removal from synthetic wastewater.

molecule. According to this model if the linearized curve passes through the origin, intraparticle diffusion plot will be the rate controlling step, but in present case, the lines of plot do not pass through the origin it shows that the intraparticle diffusion is not the only rate limiting factor in case of $\mathrm{TZ}$ removal by PPy@TN nanoparticles. ${ }^{23}$ Further, $R^{2}$ values determined for all selected concentration showed the feasibility of intraparticle diffusion model.

\subsection{Boyd model}

Removal of adsorbate molecules can also be assessed by film diffusion, so to check the possibility of film diffusion, Boyd model was also applied on kinetic data. It can be expressed by following equations: ${ }^{27}$

$$
\begin{gathered}
F=\left(1-\frac{6}{\pi^{2}}\right) \exp \left(-B_{t}\right) \\
B_{t}=-0.4977-\ln (1-F) \\
F=q_{t} / q_{\mathrm{e}}
\end{gathered}
$$

$B_{t}$ is a mathematical function of $F$, while $F$ is the fraction of dye molecule adsorbed at any time $q_{t}\left(\mathrm{mg} \mathrm{g}^{-1}\right)$ and dye molecule

Table 1 The values of different kinetic parameters for the removal of TZ by PPy@TN nanoparticles

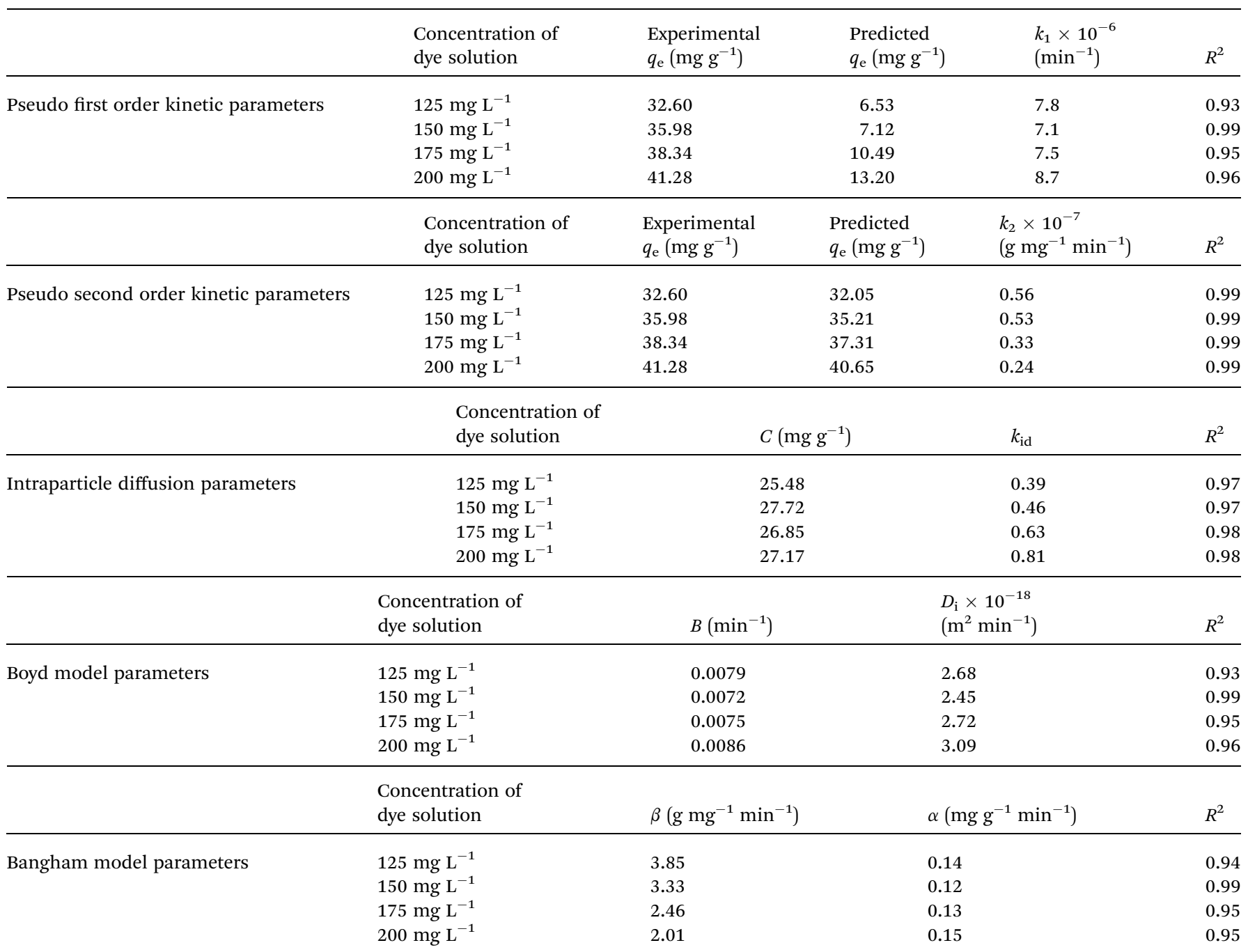



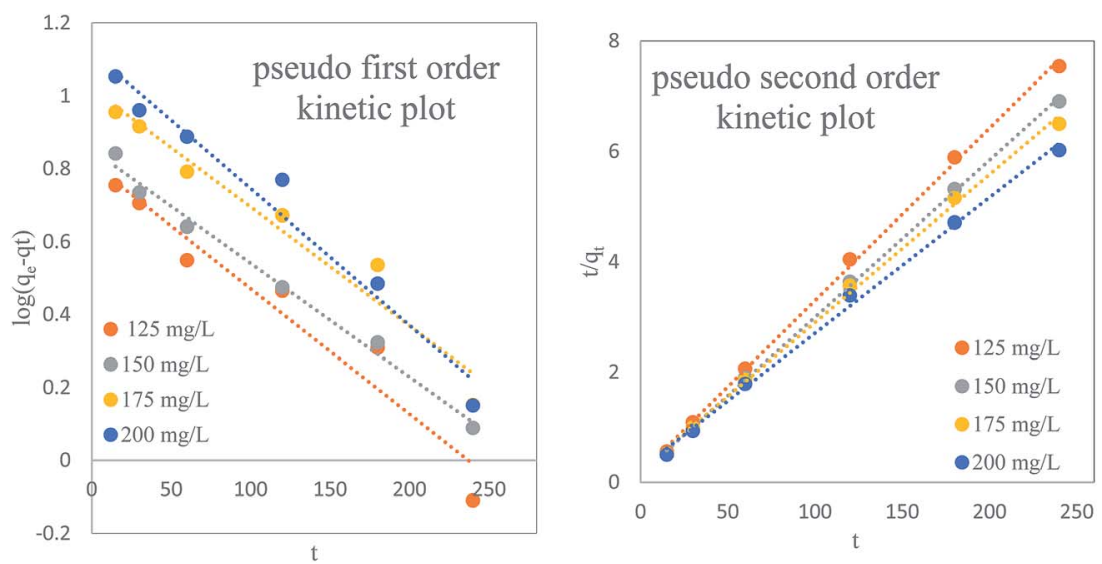

Fig. 9 (a) Pseudo first order plot (b) pseudo second order kinetic plot for TZ adsorption by PPy@TN nanoparticles.

adsorbed at equilibrium $q_{\mathrm{e}}\left(\mathrm{mg} \mathrm{g}^{-1}\right)$. The plots of $B_{t} v s$. $t$ at different initial concentrations are shown in Fig. 10b. The value of $B\left(\mathrm{~min}^{-1}\right)$ was calculated from the slope of the Boyd plot ' $B_{t}$ versus $t$ '. The linearity of Boyd plot gives an idea to distinguish between Intraparticle diffusion and film diffusion. It is clear from Boyd plot that linear plots are not passing through the origin, which indicate that adsorption process is governed by film diffusion but it is not only the rate controlling step. Value of $D_{\mathrm{i}}\left(\mathrm{m}^{2} \min ^{-1}\right)$, diffusion constant can be calculated from following equation:

$$
B=\frac{\pi^{2} D_{\mathrm{i}}}{r^{2}}
$$

where ' $r$ ' is the radius of adsorbent particles.

\subsection{Bangham's equation (pore diffusion model)}

In some cases pore diffusion may be the only rate controlling step. To check this possibility in present system, Bangham's equation was applied on kinetic data by using following equation: ${ }^{28,29}$

$$
\log \left[\log \left(\frac{C_{0}}{C_{0}-q_{t} m}\right)\right]=\log \left(\frac{k_{0} m}{2.303 V}\right)+\alpha \log (t)
$$

where $\alpha(<1)$ and $k_{0}$ are the Bangham constants. $q_{t}\left(\mathrm{mg} \mathrm{g}^{-1}\right)$ is the dye amount adsorbed at time $t, C_{0}$ is the initial dye concentration $\left(\mathrm{mg} \mathrm{L}^{-1}\right), V$ is the volume of dye solution $(\mathrm{mL}), m$ is the weight of adsorbent $\left(\mathrm{g} \mathrm{L}^{-1}\right)$. Values of Bangham parameters, $\alpha$ and $k_{0}$ were obtained from the slopes and intercepts of plot log $\left[\log \left(C_{0} /\left(C_{0}-q_{t} m\right)\right)\right]$ versus $\log t$ (Fig. 10c). The values of $\alpha$ and $k_{0}$ are given in Table 2. The plot was found to be linear for all selected concentration ranges with good correlation coefficient $(>0.9)$ indicating pore diffusion is the only rate controlling step.

\section{Effect of temperature and thermodynamic study}

Usually dye industries release effluents at different temperatures. ${ }^{30}$ The temperature has significant effect on the adsorption process, so it is necessary to investigate the effect of temperature on removal of TZ.

To study this effect, $\mathrm{TZ}$ solutions of different concentrations viz. 100,125, 150, 175 and $200 \mathrm{mg} \mathrm{L}^{-1}$ were agitated with adsorbent at four different temperatures $293,303,313$ and $323 \mathrm{~K}$ up to equilibrium. Fig. 11 depicts the effect of temperature on the removal of $\mathrm{TZ}$ from synthetic wastewater. Increased dye removal on increasing solution temperature indicates the endothermic nature of removal process. The reason of increased removal at higher temperature may be due to the increased mobility of adsorbate molecules and also due to pore enlargement which exposes more surface sites for adsorbate interaction.

Thermodynamic parameters provide important information about the mechanism of adsorbate removal. Various thermodynamic parameters viz. change in Gibbs free energy $\left(\Delta G^{\circ}\right)$, change in enthalpy $\left(\Delta H^{\circ}\right)$ and change in entropy $\left(\Delta S^{\circ}\right)$ were calculated by the following equations: ${ }^{25}$

$$
\begin{gathered}
\Delta G^{\circ}=-R T \ln k_{\mathrm{c}} \\
\Delta H^{\circ}=R\left(\frac{T_{2} T_{1}}{T_{2}-T_{1}}\right) \ln \frac{k_{\mathrm{c}_{2}}}{k_{\mathrm{c}_{1}}} \\
\Delta S^{\circ}=\frac{\Delta H^{\circ}-\Delta G^{\circ}}{T}
\end{gathered}
$$

where $\Delta G^{\circ}$ is the Gibbs free energy change $\left(\mathrm{kJ} \mathrm{mol}^{-1}\right), R$ is the universal gas constant $\left(8.314 \mathrm{~J} \mathrm{~mol}^{-1} \mathrm{~K}^{-1}\right), T$ is absolute temperature $(\mathrm{K})$ and $k_{\mathrm{c}}$ is the distribution coefficient, $C_{\mathrm{e}}$ is the equilibrium concentration of TZ dyes, $q_{\mathrm{e}}$ is the amount of TZ dyes adsorbed per unit weight of nanoparticles at equilibrium. The value of $\Delta G^{\circ}$ was determined to be $-9.06,-11.04,-12.77$ and -16.07 at $293,303,313$ and $323 \mathrm{~K}$ respectively. The negative value of $\Delta G^{\circ}$ at all selected temperatures, shows spontaneous nature of adsorption process and confirm the feasibility of TZ adsorption on PPY@TN nanoparticles. The Gibbs free energy change for physisorption is between -20 and $0 \mathrm{~kJ} \mathrm{~mol}^{-1}$ while for chemisorption it is in a range of -80 to $400 \mathrm{~kJ} \mathrm{~mol}^{-1} .{ }^{23,31}$ The values of $\Delta G^{\circ}$ obtained for present system are within the ranges of the physisorption mechanism. Further, the values of $\Delta G^{\circ}$ became more negative with raise in temperature, suggesting 

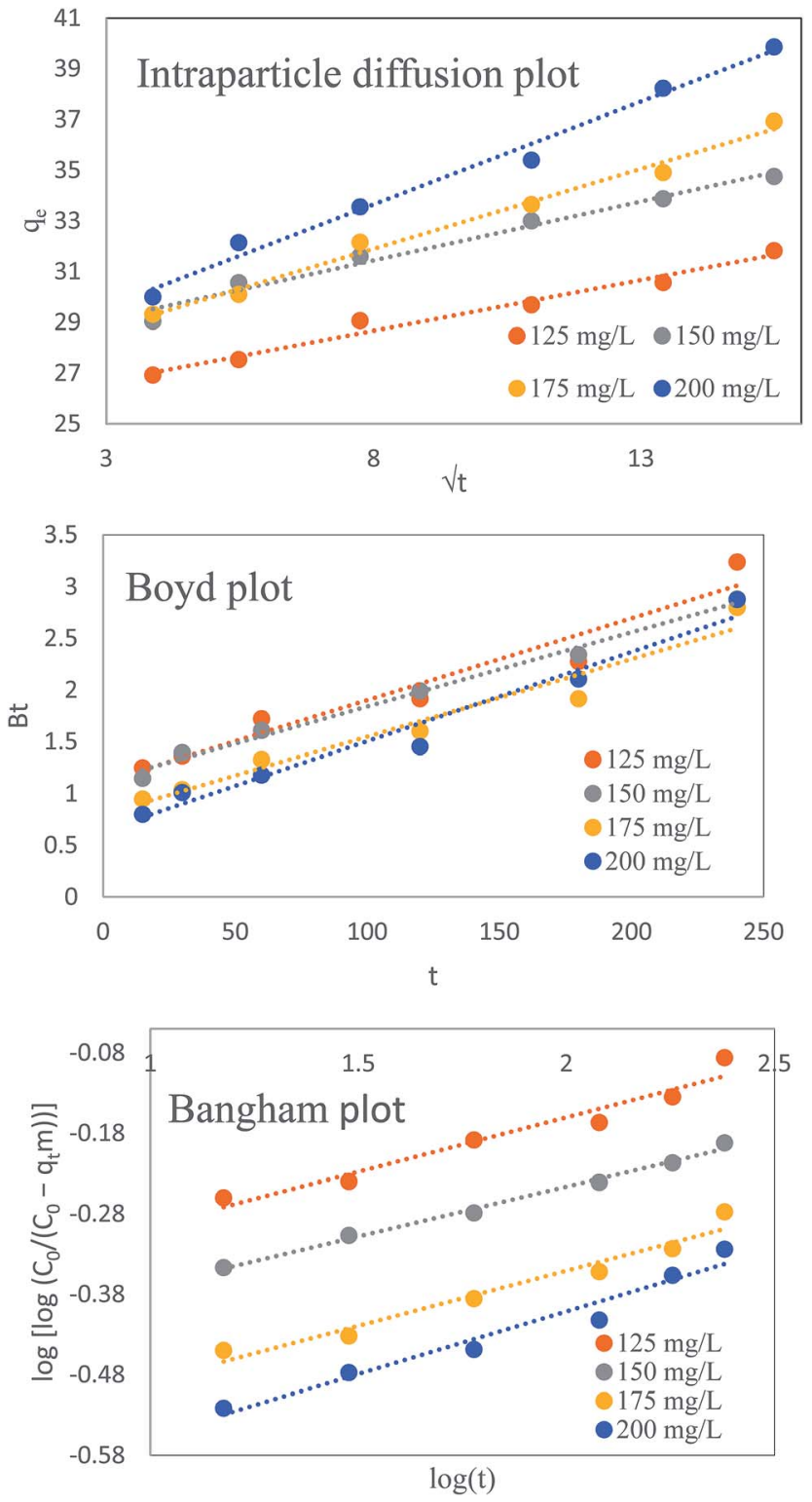

Fig. 10 (a) Intraparticle diffusion plot (b) Boyd plot (c) Bangham plot for TZ adsorption by PPy@TN nanoparticles.

that the adsorption is more favorable at higher temperatures. Positive value $\left(+1.46 \mathrm{~kJ} \mathrm{~mol}^{-1}\right)$ of $\Delta H^{\circ}$ suggested the endothermic nature of removal process which indicates that higher removal can be achieved at elevated temperature. Determination of $\Delta S^{\circ}$ is helpful for describing the randomness at the solid/solution interface during the adsorption process. Further, positive value $\left(+1491 \mathrm{~J} \mathrm{~mol}^{-1} \mathrm{~K}^{-1}\right)$ of $\Delta S^{\circ}$ showed increased randomness at the solid/solution interface during the adsorption of dyes onto nanoparticles. The positive value of $\Delta S^{\circ}$ for the $\mathrm{TZ}$ adsorption suggested higher degree of freedom of the TZ molecules with the increase of the solution temperature.

Sticking probability $\left(S^{*}\right)$ and activation energy were also calculated by using modified Arrhenius type equation: ${ }^{24}$

$$
S^{*}=(1-\theta) \mathrm{e}^{-E_{\mathrm{a}} / R T}
$$

Table 2 Values of different isotherm parameters for TZ removal by PPy@TN nanoparticles

\begin{tabular}{lrrrr}
\hline & $25{ }^{\circ} \mathrm{C}$ & $30{ }^{\circ} \mathrm{C}$ & $35{ }^{\circ} \mathrm{C}$ & $45{ }^{\circ} \mathrm{C}$ \\
\hline Langmuir isotherm parameters & & & \\
$q_{0}\left(\mathrm{mg} \mathrm{g}^{-1}\right)$ & 38.21 & 39.73 & 40.63 & 42.50 \\
$b\left(\mathrm{~L} \mathrm{mg}^{-1}\right)$ & 1.24 & 2.18 & 3.49 & 9.09 \\
$R^{2}$ & 0.67 & 0.61 & 0.60 & 0.55 \\
$\chi^{2}$ & 0.81 & 1.33 & 1.55 & 2.49 \\
& & & & \\
Freundlich isotherm parameters & & & \\
$K_{\mathrm{f}}\left(\mathrm{mg}^{1-1 / n} \mathrm{~L}^{1 / n} \mathrm{~g}^{-1}\right)$ & 25.69 & 27.41 & 28.99 & 31.80 \\
$n\left(\mathrm{~g} \mathrm{~L}^{-1}\right)$ & 9.52 & 9.43 & 9.82 & 10.11 \\
$R^{2}$ & 0.91 & 0.88 & 0.87 & 0.82 \\
$\chi^{2}$ & 0.22 & 0.46 & 0.53 & 1.09
\end{tabular}

Dubinin-Radushkevich (D-R) isotherm parameters

$\begin{array}{lrrrr}q \mathrm{~m}\left(\mathrm{mg} \mathrm{g}^{-1}\right) & 37.18 & 38.96 & 40.04 & 42.18 \\ \beta\left(\mathrm{mol}^{2} \mathrm{~kJ}^{-2}\right) & 1.97 & 0.79 & 0.40 & 0.13 \\ E\left(\mathrm{~kJ} \mathrm{~mol}^{-1}\right) & 0.50 & 0.79 & 1.11 & 1.93 \\ R^{2} & 0.56 & 0.54 & 0.55 & 0.52 \\ \chi^{2} & 1.03 & 1.54 & 1.74 & 2.62\end{array}$

Redlich-Peterson (R-P) isotherm parameters

$\begin{array}{lcccc}a_{\mathrm{RP}}\left(\mathrm{L} \mathrm{g}^{-1}\right) & 0.16 & 0.24 & 0.26 & 0.48 \\ b_{\mathrm{RP}}\left(\mathrm{L} \mathrm{g}^{-1}\right) & 28.27 & 29.14 & 29.73 & 30.34 \\ g & 0.024 & 0.019 & 0.027 & 0.013 \\ R^{2} & 0.99 & 0.99 & 0.98 & 0.99 \\ \chi^{2} & 0.01 & 0.02 & 0.04 & 0.04\end{array}$

Sips isotherm parameters

\begin{tabular}{lcccc}
$q_{\mathrm{m}}\left(\mathrm{mg} \mathrm{g}^{-1}\right)$ & 19.49 & 20.05 & 22.55 & 25.97 \\
$K_{\mathrm{S}}\left(\mathrm{L} \mathrm{mg}^{-1}\right)$ & 8.63 & 12.08 & 7.69 & 5.29 \\
$m_{\mathrm{S}}$ & 0.104 & 0.106 & 0.101 & 0.098 \\
$R^{2}$ & 0.91 & 0.87 & 0.88 & 0.82 \\
$\chi^{2}$ & 0.22 & 0.46 & 0.53 & 1.09 \\
\hline
\end{tabular}

The $S^{*}$ is a function of the adsorbate/adsorbent system which is dependent on the temperature of the system and the value of $S^{*}$ lies in the range $0<S^{*}<1 . E_{\mathrm{a}}$ is activation energy and calculated from the slope of the plot of $\ln (1-\theta)$ versus $1 / T$. The value of $\theta$ can be calculated from the following equation:

$$
\theta=\left[1-\frac{C_{\mathrm{e}}}{C_{0}}\right]
$$

The value of activation energy gives an idea about the nature of adsorption process. In case of involvement of physical adsorption, activation energy lies in the range of 5$40 \mathrm{~kJ} \mathrm{~mol}^{-1}$ while for chemical adsorption, the values vary from $40-800 \mathrm{~kJ} \mathrm{~mol}^{-1}$. The value of $E_{\mathrm{a}}$ for present system was found to be $26.97 \mathrm{~kJ} \mathrm{~mol}^{-1}$ suggesting that physisorption is the predominant mechanism which is involved in $\mathrm{TZ}$ adsorption. Value of sticking probability was determined to be $2.3 \times 10^{-4}$.

\section{Isotherm modelling}

Equilibrium adsorption isotherm represents the relation between concentration of adsorbate in the liquid phase and on the adsorbent surface. Adsorption isotherm is also helpful to 
describe interaction between adsorbent surface/adsorbate species and determine the maximum adsorption capacity. ${ }^{32}$ For obtaining equilibrium data, experiments were carried out with different dye concentrations (100 to $\left.200 \mathrm{mg} \mathrm{L}^{-1}\right)$ at different temperatures. Several isotherm models viz. Langmuir,

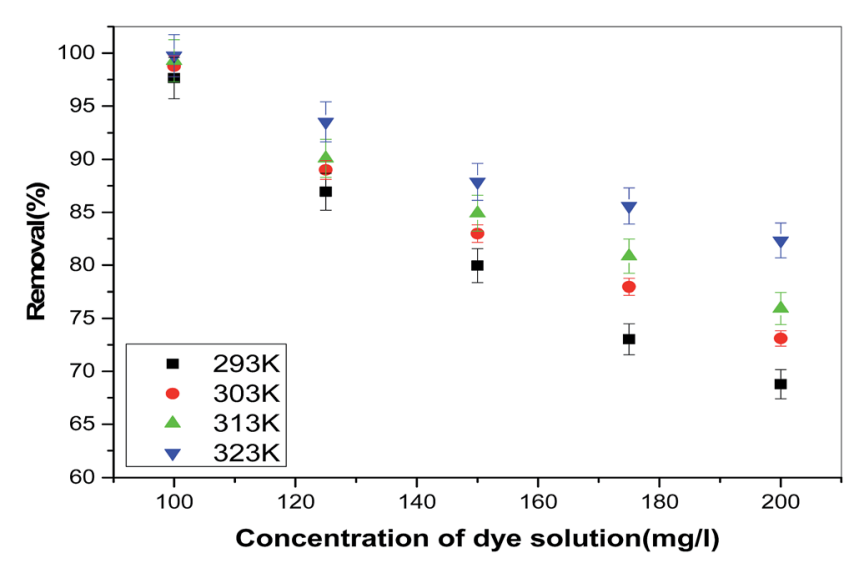

Fig. 11 Effect of temperature on removal of TZ from synthetic wastewater.
Freundlich, Redlich-Peterson, Dubinin-Radushkevich and Sips isotherm model were applied on the equilibrium data.

\subsection{Langmuir isotherm model}

According to Langmuir isotherm, adsorption takes place at specific sites on the adsorbent surface and the adsorption energy is homogeneously distributed on the adsorbent surface. ${ }^{33}$ Molecular interaction is not possible between adsorbed molecular species. The Langmuir isotherm can be expressed as follows:

$$
q_{\mathrm{e}}=\frac{q_{\mathrm{m}} b C_{\mathrm{e}}}{\left(1+b C_{\mathrm{e}}\right)}
$$

where $q_{\mathrm{m}}\left(\mathrm{mg} \mathrm{g}^{-1}\right)$ is the maximum adsorption capacity of PPy@TN nanoparticles and $b$ is the Langmuir constant $\left(\mathrm{L} \mathrm{mg}^{-1}\right) \cdot C_{\mathrm{e}}\left(\mathrm{mg} \mathrm{L}^{-1}\right)$ and $q_{\mathrm{e}}\left(\mathrm{mg} \mathrm{g}^{-1}\right)$ are the equilibrium concentration of dye and adsorption capacity of nanoparticles at equilibrium respectively.

\subsection{Freundlich isotherm model}

Freundlich isotherm assumes heterogeneous distribution of active sites and also supports for multilayer adsorption. ${ }^{34}$
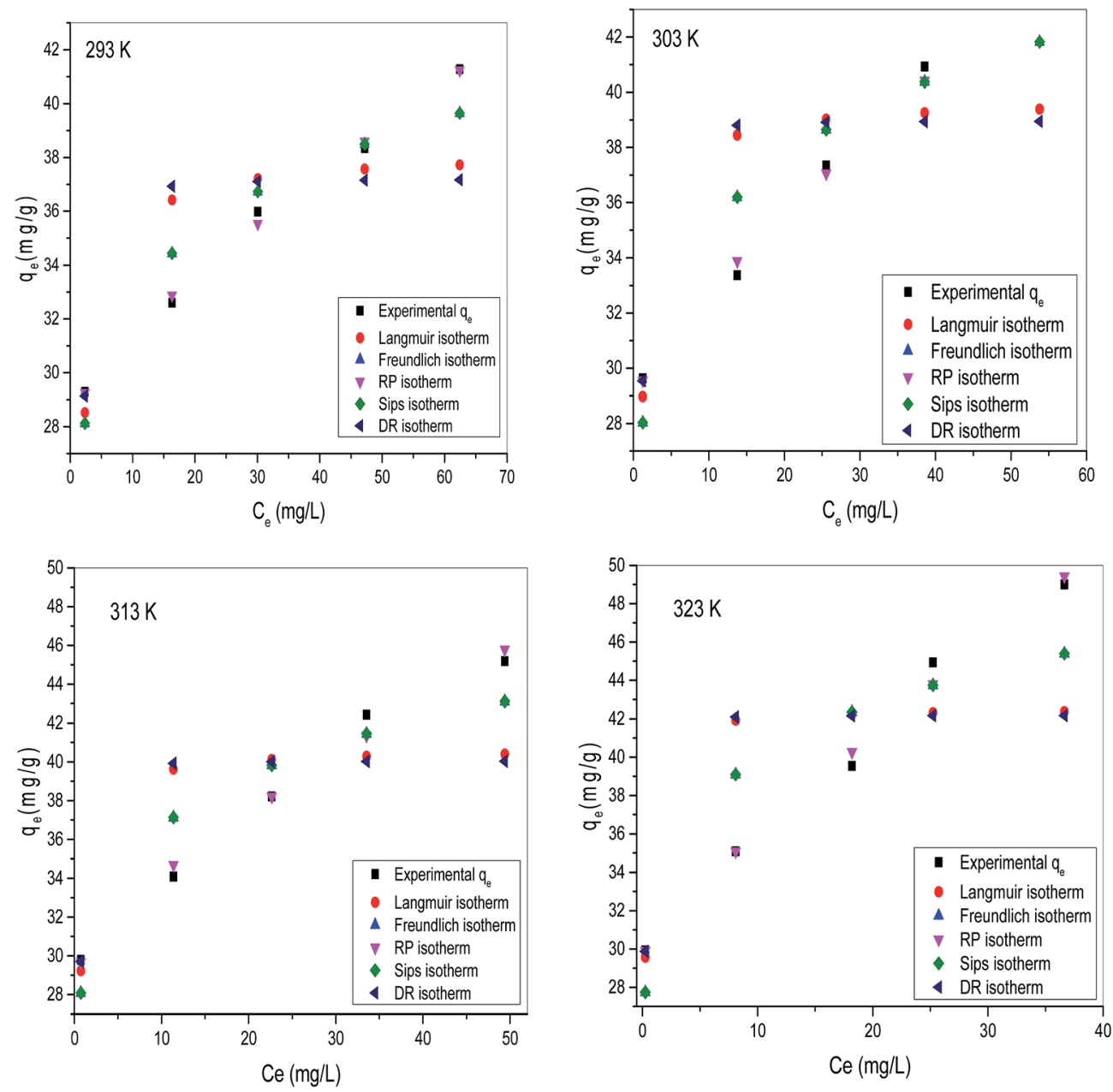

Fig. 12 Nonlinear isotherm plot for the adsorption of tartrazine on nanoparticles (a) 293 K; (b) 303 K; (c) 313 K; (d) 323 K. 


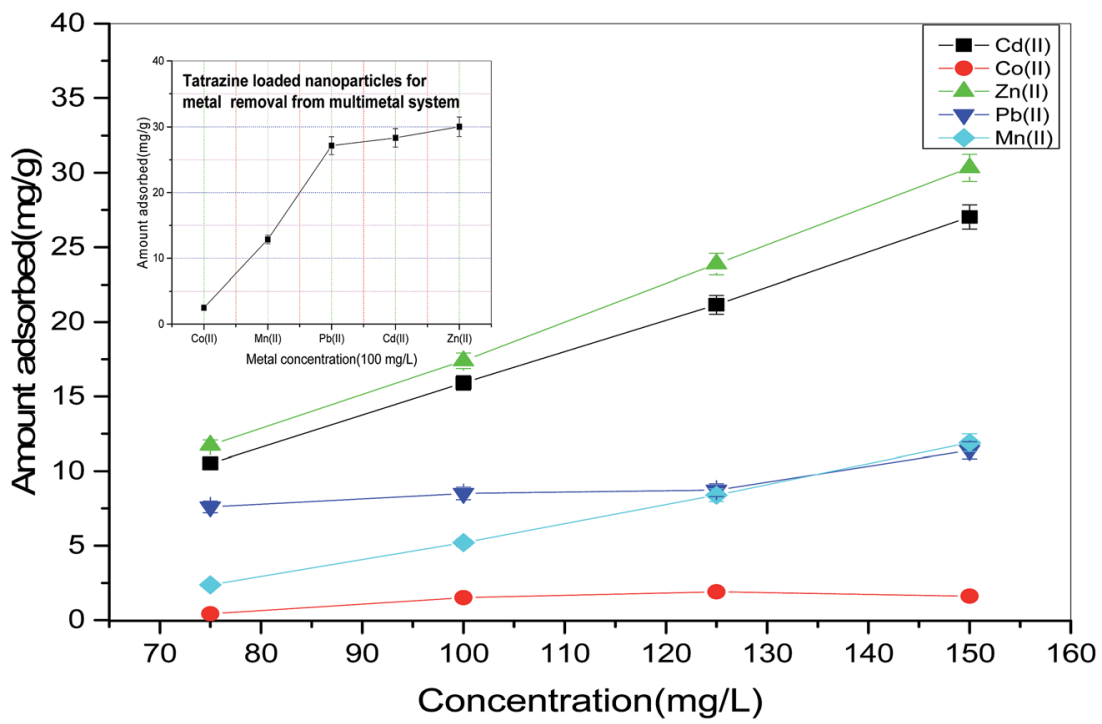

Fig. 13 Removal of metals from single solute and multisolute synthetic wastewater.

According to Freundlich isotherm interactions are possible between adsorbed molecules. The Freundlich isotherm model is represented by following equation:

$$
q_{\mathrm{e}}=K_{\mathrm{f}} C^{\frac{1}{n}}
$$

where $K_{\mathrm{f}}\left(\mathrm{mg} \mathrm{g}^{-1}\left(\mathrm{~L} \mathrm{mg}^{-1}\right)^{1 / n}\right)$ and $1 / n$ are Freundlich constants related with adsorption capacity and the heterogeneity factor. Value of $1 / n$ gives an idea about the type of isotherm to be irreversible $(1 / n=0)$, favorable $(0<1 / n<1)$ and unfavorable $(1 / n>1)$.

\subsection{Dubinin and Radushkevich isotherm model}

Dubinin and Radushkevich isotherm is helpful in the determination of adsorption energy $\mathrm{and}^{\mathbf{3 0}}$ can be expressed as follows: ${ }^{35}$

$$
\begin{gathered}
q_{\mathrm{e}}=q_{\mathrm{m}} \exp \left(-\beta \varepsilon^{2}\right) \\
\varepsilon=R T \ln \left(1+\frac{1}{C_{\mathrm{e}}}\right) \\
E=\frac{1}{\sqrt{2 \beta}}
\end{gathered}
$$

where $q_{\mathrm{m}}$ is the maximum adsorption capacity $\left(\mathrm{mg} \mathrm{g}^{-1}\right) ; R$ is the gas constant ( $8.314 \mathrm{~J} \mathrm{~mol}^{-1} \mathrm{~K}^{-1}$ ); $T$ is the absolute temperature and constant $\beta\left(\mathrm{mol}^{2} \mathrm{~kJ}^{-2}\right.$ ) gives the mean free energy. $\varepsilon$ is the Polanyi potential and $E$ is related to the mean free energy of the adsorption per mole of the adsorbate $\left(\mathrm{kJ} \mathrm{mol}^{-1}\right)$.

\subsection{Sips isotherm}

The Sips isotherm is a combination of Langmuir and Freundlich isotherm and can be expressed as follows:

$$
q_{\mathrm{e}}=\frac{q_{\mathrm{m}}\left(K_{\mathrm{S}} C_{\mathrm{e}}\right)^{m_{\mathrm{S}}}}{1+\left(K_{\mathrm{S}} C_{\mathrm{e}}\right)^{m_{\mathrm{S}}}}
$$

where $q_{\mathrm{m}}$ is the Sips maximum adsorption capacity $\left(\mathrm{mg} \mathrm{g}^{-1}\right), K_{\mathrm{S}}$ is the Sips equilibrium constant $\left(\mathrm{L} \mathrm{mg}^{-1}\right)$, and $m_{\mathrm{S}}$ is the Sips model exponent. In case of low adsorbate concentrations, it reduces to Freundlich isotherm while for high adsorbate concentrations, it behaves like Langmuir isotherm. ${ }^{36}$

\subsection{Redlich-Peterson isotherm}

The Redlich-Peterson isotherm can be applied for both homogeneous and heterogeneous systems. ${ }^{37}$ The RedlichPeterson isotherm can be represented by the following equation:

$$
q_{\mathrm{e}}=\frac{k_{\mathrm{RP}} C_{\mathrm{e}}}{1+a_{\mathrm{RP}} C_{\mathrm{e}}{ }^{\beta}}
$$

where $k_{\mathrm{RP}}$ and $a_{\mathrm{RP}}$ are the Redlich-Peterson constants $\left(\mathrm{L} \mathrm{g}^{-1}\right)$ and $\left(\mathrm{L} \mathrm{mg}^{-1}\right)$ and $\beta$ an exponent that lies between 0 and 1 . The isotherm parameters were determined by nonlinear regression, using the Microsoft excel solver 2010. The coefficient of determination $R^{2}$ helps in the determination of best fit isotherm model which was calculated from the following equation: ${ }^{38}$

$$
R^{2}=\frac{\sum\left(q_{\mathrm{m}}-\overline{q_{\mathrm{e}}}\right)^{2}}{\sum\left(q_{\mathrm{m}}-\overline{q_{\mathrm{e}}}\right)^{2}+\sum\left(q_{\mathrm{m}}-q_{\mathrm{e}}\right)^{2}}
$$

where $q_{\mathrm{e}}$ is the equilibrium adsorption capacity determined by experiments, $q_{\mathrm{m}}$ is the isotherm predicted equilibrium adsorption capacity. The nonlinear isotherm plots for different isotherms are shown in Fig. 12a-d and the parameters calculated for different isotherm models are summarized in Table 2. $\chi^{2}$ value was determined for different isotherms to predict best model among all studied isotherms by using following equation. ${ }^{25}$

$$
\text { The chi square } \chi^{2}=\sum \frac{\left(q_{\mathrm{e}, \text { exp }}-q_{\mathrm{e}, \mathrm{cal}}\right)^{2}}{q_{\mathrm{e}, \mathrm{cal}}}
$$


where $q_{\mathrm{e}, \mathrm{exp}}$ and $q_{\mathrm{e}, \mathrm{cal}}$ are the equilibrium capacity calculated from experiments and calculated by isotherm model respectively. On comparing $R^{2}$ and $\chi^{2}$ values for all isotherms, Redlich-Peterson (R-P) isotherm was found to be best fit isotherm model for describing TZ adsorption on PPy@TN nanoparticles.

\section{Comparative study}

Comparative study for the removal efficiency of polypyrrole coated nanoparticles with other available adsorbent materials for tartrazine was also carried out. Adsorption capacity of bottom ash and de-oiled ash for tartrazine dye was determined to be $2.358 \times 10^{-5}$ and $4.608 \times 10^{-5} \mathrm{~mol} \mathrm{~g}^{-1}$ respectively. ${ }^{10} \mathrm{In}$ another study, hen feather was used as an adsorbent material for the removal of tartrazine and its adsorption capacity was observed to be $0.00014\left(\mathrm{~mol} \mathrm{~g}^{-1}\right) .^{6}$ Banerjee and Chattopadhyaya (2013) investigated efficiency of saw dust for tartrazine dye. ${ }^{39}$ Langmuir adsorption capacity of saw dust was

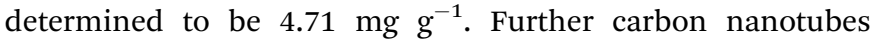
decorated with silver nanoparticles were synthesized for tartrazine removal and it was found very efficient for the tartrazine adsorption (85.09 $\left.\mathrm{mg} \mathrm{g}^{-1}\right) .^{9}$ Adsorption capacity of commercial activated carbon (CAC), coconut shell activated carbon (CSAC) and Lantana carbon was reported to be 4.484, 2.257 and $90.9 \mathrm{mg}$ $\mathrm{g}^{-1}$ respectively. ${ }^{40,41}$ In another study polyaniline nanolayer composite was synthesized by Ansari et al. ${ }^{42}$ Adsorption capacity of polyaniline nanolayer composite was found to be 2.47 $\mathrm{mg} \mathrm{g}^{-1}$. It is clear from comparative study that the adsorption capacity of synthesized polypyrrole coated tenorite nanoparticle $\left(42.50 \mathrm{mg} \mathrm{g}^{-1}\right)$ is quite comparable with the other available adsorbent materials.

\section{Metal removal from synthetic wastewater}

In the present study, tartrazine dye loaded adsorbent (TZ-PPy@TN) was used as an adsorbent material for the removal of $\mathrm{Co}(\mathrm{II}), \mathrm{Mn}(\mathrm{II}), \mathrm{Pb}$ (II), $\mathrm{Cd}(\mathrm{II})$ and $\mathrm{Zn}$ (II) metals from single and multisolute system.

Tartrazine dye loaded on nanoparticles acts as modifying agent which makes nanoparticles surface suitable for metal adsorption. ${ }^{43}$ Adsorption capacity of TZ loaded nanoparticles (TZ-PPy@TN) for different metals is shown in Fig. 13. It can be observed in Fig. 13 that a wide range of metal concentrations can be efficiently treated with TZ loaded nanoparticles. Following trend was observed in the single solute system.

$$
\mathrm{Co} \text { (II) }<\mathrm{Mn} \text { (II) }<\mathrm{Pb} \text { (II) }<\mathrm{Cd} \text { (II) }<\mathrm{Zn} \text { (II) }
$$

A similar trend was also observed in case of multi-solute metal solution of these metallic species. Adsorption of different metallic species depends on different factors viz. speciation of metallic species, degree of ionization etc. Detailed study is recommended for complete illustration of metal-TZ loaded nanoparticle interaction.

\section{Conclusions}

Following conclusions may be drawn from the present study.

(i) Polypyrrole coated tenorite nanoparticles with $30 \mathrm{~nm}$ diameter and $425 \mathrm{~m}^{2} \mathrm{~g}^{-1}$ BET surface area were successfully synthesized.

(ii) TEM images showed the formation of brick like structure in polypyrrole coated tenorite nanoparticles.

(iii) Synthesized nanoparticles were found to be very efficient for the removal of dye in all the selected concentration ranges.

(iv) pH study reveals that maximum removal can be achieved at $2.0 \mathrm{pH}$ as adsorbent surface supports dye anion adsorption due to positively charged surface in acidic medium.

(v) Dye removal increased on increasing the temperature, which shows endothermic nature of the removal process.

(vi) The negative value of $\Delta G^{\circ}$ at all temperatures suggest the feasibility of tartrazine adsorption on polypyrrole coated tenorite nanoparticles.

(vii) Dye loaded nanoparticles were used as an efficient adsorbent for different metallic species from the single and multisolute system.

Present study indicates the versatile nature of the polypyrrole coated tenorite nanoparticles because it was found to be efficient for tartrazine dye as well as for metallic species which make it a strong candidate for the treatment of dye laden and metal bearing wastewater.

\section{Acknowledgements}

The authors are thankful to the Regional Council of South-Savo and the City of Mikkeli for funding and Mikkeli University of Applied Sciences for providing SEM analysis of samples.

\section{References}

1 A. Rodríguez, J. García, G. Ovejero and M. Mestanza, J. Hazard. Mater., 2009, 172, 1311-1320.

2 E. T. Acar, S. Ortaboy and G. Atun, Chem. Eng. J., 2015, 276, 340-348.

3 S. J. Allen, G. Mckay and J. F. Porter, J. Colloid Interface Sci., 2004, 280, 322-333.

4 A. González, M. E. Villanueva, L. L. Piehl and G. J. Copello, Chem. Eng. J., 2015, 280, 41-48.

5 G. L. Dotto, J. M. Moura, T. R. S. Cadaval and L. A. A. Pinto, Chem. Eng. J., 2013, 214, 8.

6 A. Mittal, L. Kurup and J. Mittal, J. Hazard. Mater., 2007, 146(1-2), 243.

7 C. Klett, A. Barry, I. Balti, P. Lelli, F. Schoenstein and N. Jouini, J. Environ. Chem. Eng., 2014, 2, 914-926.

8 M. Wawrzkiewicz and Z. Hubicki, J. Hazard. Mater., 2009, 164(2-3), 502.

9 J. Goscianska and R. Pietrzak, Catal. Today, 2015, 249, 259264.

10 A. Mittal, J. Mittal and L. Kurup, J. Hazard. Mater., 2006, 136(3), 567.

11 W. Brostow, H. E. Hagg Lobland, S. Pal and R. P. Singh, J. Mater. Educ., 2009, 31, 157. 
12 Á. Sánchez-Sánchez, F. Suárez-García, A. Martínez-Alonso and J. M. D. Tascón, J. Colloid Interface Sci., 2015, 450, 91100.

13 H. Mittal, A. Maity and S. S. Ray, Int. J. Biol. Macromol., 2015, $79,8$.

14 G. Akkaya Sayğılı, J. Mol. Liq., 2015, 211, 515-526.

15 D. A. Giannakoudakis, G. Z. Kyzas, A. Avranas and N. K. Lazaridis, J. Mol. Liq., 2015, DOI: 10.1016/ j.molliq.2015.07.010.

16 F. Motahari, M. R. Mozdianfard and M. Salavati-Niasari, Process Saf. Environ. Prot., 2015, 93, 282.

17 L. Lian, X. Cao, Y. Wu, D. Lou and D. Han, J. Taiwan Inst. Chem. Eng., 2013, 44(1), 67.

18 S. Mohammadi and G. Khayatian, Spectrochim. Acta, Part A, 2015, 148, 405.

19 S. Dadfarnia, A. M. Haji Shabani, S. E. Moradi and S. Emami, Appl. Surf. Sci., 2015, 330, 85.

20 E. Tahmasebi, Y. Yamini, S. Seidi and M. Rezazadeh, J. Chromatogr. A, 2013, 1314, 15-23.

21 M. B. Gholivand, Y. Yamini, M. Dayeni, S. Seidi and E. Tahmasebi, J. Environ. Chem. Eng., 2015, 3(1), 529.

22 S. Yadav, V. Srivastava, S. Banerjee, C. H. Weng and Y. C. Sharma, Catena, 2013, 100, 120.

23 N. M. Mahmoodi, B. Hayati, M. Arami and H. Bahrami, Desalination, 2011, 275(1-3), 93.

24 T. G. Venkatesha, Y. A. Nayaka and B. K. Chethana, Appl. Surf. Sci., 2013, 276, 620.

25 V. Srivastava, Y. C. Sharma and M. Sillanpää, Appl. Surf. Sci., 2015, 338, 42.

26 W. J. Weber and J. C. Morris, J. Sanit. Eng. Div., Am. Soc. Civ. Eng., 1963, 89, 31.
27 G. E. Boyd, A. W. Adamson and L. S. Myers, J. Am. Chem. Soc., 1947, 69, 2836-2848.

28 D. H. Bangham and F. P. Burt, Proc. R. Soc. London, Ser. A, 1924, 105, 481-488.

29 V. S. Mane, I. Deo Mall and V. Chandra Srivastava, J. Environ. Manage., 2007, 84(4), 390.

30 M. Ghaedi, B. Sadeghian, A. A. Pebdani, R. Sahraei, A. Daneshfar and C. Duran, Chem. Eng. J., 2012, 187, 133.

31 S. Zeng, S. Duan, R. Tang, L. Li, C. Liu and D. Sun, Chem. Eng. J., 2014, 258, 218.

32 R. Chen, W. Wang, X. Zhao, Y. Zhang, S. Wu and F. Li, Chem. Eng. J., 2014, 242, 226.

33 I. Langmuir, J. Am. Chem. Soc., 1916, 38, 2221-2295.

34 H. M. F. Freundlich, J. Phys. Chem., 1906, 57, 385-471.

35 M. M. Dubinin and L. V. Radushkevich, Proc. Acad. Sci. USSR, Phys. Chem. Sect., 1947, 55, 331-337.

36 T. Madrakian, A. Afkhami and M. Ahmadi, Spectrochim. Acta, Part A, 2012, 99, 102.

37 O. Redlich and D. L. Peterson, J. Phys. Chem., 1959, 63(6), 1024.

38 Y. S. Ho, Pol. J. Environ. Stud., 2006, 15(1), 81.

39 S. Banerjee and M. C. Chattopadhyaya, Arabian J. Chem., 2013, DOI: 10.1016/j.arabjc.2013.06.005.

40 M. Jibril, J. Noraini, L. S. Poh and A. M. Evuti, Jurnal Teknologi, 2013, 60, 15.

41 R. K. Gautam, P. K. Gautam, S. Banerjee, V. Rawat, S. Soni, S. K. Sharma and M. C. Chattopadhyaya, J. Environ. Chem. Eng., 2015, 3(1), 79.

42 R. Ansari, M. B. Keivani and A. F. Delavar, J. Polym. Res., 2011, 18(6), 1931.

43 L. Monser and N. Adhoum, J. Hazard. Mater., 2009, 161(1), 263. 